\title{
Theoretical and electron paramagnetic resonance studies of hyperfine interaction in nitrogen doped $4 \mathrm{H}$ and $6 \mathrm{H} \mathrm{SiC}$
}

K. Szasz, Xuan Thang Trinh, Nguyen Tien Son, Erik Janzén and A. Gali

\section{Linköping University Post Print}

\section{Tweet}

N.B.: When citing this work, cite the original article.

Original Publication:

K. Szasz, Xuan Thang Trinh, Nguyen Tien Son, Erik Janzén and A. Gali, Theoretical and electron paramagnetic resonance studies of hyperfine interaction in nitrogen doped $4 \mathrm{H}$ and $6 \mathrm{H}$ SiC, 2014, Journal of Applied Physics, (115), 7, 073705.

http://dx.doi.org/10.1063/1.4866331

Copyright: American Institute of Physics (AIP) http://www.aip.org/

Postprint available at: Linköping University Electronic Press http://urn.kb.se/resolve?urn=urn:nbn:se:liu:diva-105753 


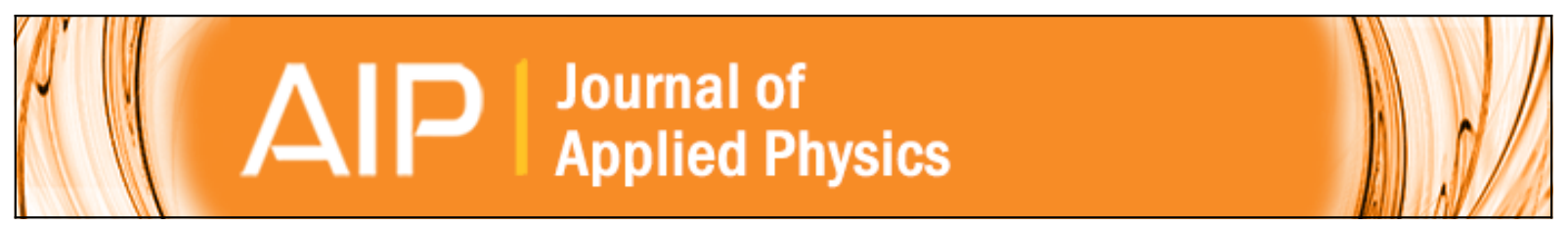

Theoretical and electron paramagnetic resonance studies of hyperfine interaction in nitrogen doped $4 \mathrm{H}$ and $6 \mathrm{H}$ SiC

K. Szász, X. T. Trinh, N. T. Son, E. Janzén, and A. Gali

Citation: Journal of Applied Physics 115, 073705 (2014); doi: 10.1063/1.4866331

View online: http://dx.doi.org/10.1063/1.4866331

View Table of Contents: http://scitation.aip.org/content/aip/journal/jap/115/7?ver=pdfcov

Published by the AIP Publishing

\section{Articles you may be interested in}

Theory of hyperfine active nitrogen complexes observed in $4 \mathrm{H}-\mathrm{SiC}$ diodes

J. Appl. Phys. 114, 113712 (2013); 10.1063/1.4821799

Electron paramagnetic resonance and theoretical studies of $\mathrm{Nb}$ in $4 \mathrm{H}$ - and $6 \mathrm{H}-\mathrm{SiC}$

J. Appl. Phys. 112, 083711 (2012); 10.1063/1.4759362

X-ray diffraction and electron paramagnetic resonance study of porous $6 \mathrm{H}-\mathrm{SiC}$

J. Vac. Sci. Technol. B 27, 849 (2009); 10.1116/1.3043462

Peculiarities of neutron-transmutation phosphorous doping of Si 30 enriched SiC crystals: Electron paramagnetic resonance study

J. Appl. Phys. 102, 063713 (2007); 10.1063/1.2783884

Photoexcitation-electron-paramagnetic-resonance studies of the carbon vacancy in $4 \mathrm{H}-\mathrm{SiC}$

Appl. Phys. Lett. 81, 3945 (2002); 10.1063/1.1522822

\section{AlP Re-register for Table of Content Alerts}




\title{
Theoretical and electron paramagnetic resonance studies of hyperfine interaction in nitrogen doped $4 \mathrm{H}$ and $6 \mathrm{H} \mathrm{SiC}$
}

\author{
K. Szász, ${ }^{1,2, a)}$ X. T. Trinh, ${ }^{3}$ N. T. Son, ${ }^{3}$ E. Janzén, ${ }^{3}$ and A. Gali ${ }^{1,4, b)}$ \\ ${ }_{1}^{1}$ Institute for Solid State Physics and Optics, Wigner Research Centre for Physics, \\ Hungarian Academy of Sciences, P.O. Box 49, H-1525 Budapest, Hungary \\ ${ }^{2}$ Institute of Physics, Loránd Eötvös University, Pázmány Péter sétány 1/A, H-1117 Budapest, Hungary \\ ${ }^{3}$ Department of Physics, Chemistry and Biology, Linköping University, SE-581 83 Linköping, Sweden \\ ${ }^{4}$ Department of Atomic Physics, Budapest University of Technology and Economics, Budafoki út 8., \\ H-1111 Budapest, Hungary
}

(Received 29 November 2013; accepted 7 February 2014; published online 21 February 2014)

\begin{abstract}
Motivated by recent experimental findings on the hyperfine signal of nitrogen donor $\left(\mathrm{N}_{\mathrm{C}}\right)$ in $4 H$ and $6 \mathrm{H} \mathrm{SiC}$, we calculate the hyperfine tensors within the framework of density functional theory. We find that there is negligible hyperfine coupling with ${ }^{29} \mathrm{Si}$ isotopes when $\mathrm{N}_{\mathrm{C}}$ resides at $h$ site both in $4 H$ and $6 H \mathrm{SiC}$. We observe measurable hyperfine coupling to a single ${ }^{29} \mathrm{Si}$ at $k$ site in $4 H \mathrm{SiC}$ and $k_{1}$ site in $6 \mathrm{H} \mathrm{SiC}$. Our calculations unravel that such ${ }^{29} \mathrm{Si}$ hyperfine coupling does not occur at $k_{2}$ site in $6 \mathrm{H} \mathrm{SiC}$. Our findings are well corroborated by our new electron paramagnetic resonance studies in nitrogen doped 6 H SiC. (c) 2014 AIP Publishing LLC. [http://dx.doi.org/10.1063/1.4866331]
\end{abstract}

\section{INTRODUCTION}

Silicon carbide $(\mathrm{SiC})$ is a promising semiconductor for high-temperature, high-power electronic devices. The most common dopant in $\mathrm{SiC}$ is nitrogen $\left({ }^{14} \mathrm{~N}\right.$, natural abundance: $99.6 \%$, nuclear spin: $I=1$ ), which introduces shallow donor levels in the band gap causing $n$-type conductivity. ${ }^{1}$ Recently, it has been found that $\mathrm{SiC}$ is able to host solid state quantum bits ${ }^{2}$ and single photon emitters. ${ }^{3}$ Awshalom's group has showed that the most common polytypes $(3 \mathrm{C}, 4 \mathrm{H}$, $6 \mathrm{H}$ ) of $\mathrm{SiC}$ can possess coherent and optically manipulable defect spin states. ${ }^{4}$ The coherence time may be reduced by $\mathrm{N}$ donors with $S=1 / 2$ spin. For these reasons, it is essential to understand deeply the electronic and magnetic properties of the $\mathrm{N}$ donor in $\mathrm{SiC}$.

The $\mathrm{N}$ donor impurity in $\mathrm{SiC}$ is a complex problem since $\mathrm{N}$ might reside at carbon (C) or silicon (Si) sites. Moreover, $\mathrm{N}$ can substitute several inequivalent lattice sites: In $4 H \mathrm{SiC}$, there are two inequivalent sites, the hexagonal $(h)$ and the quasi-cubic $(k)$, denoted as $\mathrm{N}_{\mathrm{C}}(h)$ and $\mathrm{N}_{\mathrm{C}}(k)$, respectively, when $\mathrm{N}$ substitutes carbon atom in $\mathrm{SiC}$ lattice. $6 \mathrm{H} \mathrm{SiC}$ has three inequivalent sites, namely the hexagonal $(h)$ and two quasi-cubic $\left(k_{1}\right.$ and $\left.k_{2}\right)$, denoted as $\mathrm{N}_{\mathrm{C}}(h), \mathrm{N}_{\mathrm{C}}\left(k_{1}\right)$, and $\mathrm{N}_{\mathrm{C}}\left(k_{2}\right)$, respectively. The ionization energy of $\mathrm{N}$ on the hexagonal site (in $4 H \mathrm{SiC} 66 \mathrm{meV}$, in $6 H \mathrm{SiC} 100 \mathrm{meV}$ ) is much shallower than that of center on the quasi-cubic site (in $4 H \mathrm{SiC} 124 \mathrm{meV}$, in $6 H \mathrm{SiC} 155 \mathrm{meV}) .^{5}$ The ab initio calculated ionization energies for $\mathrm{N}_{\mathrm{C}} \mathrm{s}$ are in good agreement with the above mentioned data, supporting the fact that $\mathrm{N}$ preferentially resides at the $\mathrm{C}$ sites and not the $\mathrm{Si}$ sites. ${ }^{6}$ This statement is also confirmed by previous density functional theory calculations predicting that $\mathrm{N}_{\mathrm{C}}$ is favorable over $\mathrm{N}_{\mathrm{Si}}$ by more than $5 \mathrm{eV}$, so the concentration of $\mathrm{N}_{\mathrm{Si}}$ is negligible. ${ }^{7-9}$

\footnotetext{
${ }^{a)}$ Electronic mail: szasz.krisztian@wigner.mta.hu

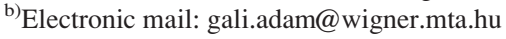

Studying the spin density of the $\mathrm{N}$ donor in hexagonal $\mathrm{SiC}$ is the key to understand the physical properties of the system. The spin density distribution can be mapped by electron paramagnetic resonance (EPR) or electron-nuclear double resonance (ENDOR) by means of the interaction between the donor electron spin and the nuclear spin of ${ }^{13} \mathrm{C}$ $(1.1 \%, I=1 / 2)$ and ${ }^{29} \mathrm{Si}(4.7 \%, I=1 / 2)$ isotopes. This results in hyperfine (hf) signals, which reveals the distribution of the electron spin density around the $\mathrm{N}$ donor. The hf interaction with $\mathrm{N}$ was first reported in Ref. 10: In both $4 \mathrm{H}$ an $6 \mathrm{H}$ $\mathrm{SiC}$, this interaction is weak for $\mathrm{N}_{\mathrm{C}}(h)$, and strong when $\mathrm{N}$ resides at the quasi-cubic sites. However, the previous results about the hf structure of $\mathrm{N}$ donor for proximate ${ }^{13} \mathrm{C}$ and ${ }^{29} \mathrm{Si}$ isotopes in $4 H$ and $6 H \mathrm{SiC}$ (Refs. 10-14) are contradictory. In $4 H \mathrm{SiC}$ for $\mathrm{N}_{\mathrm{C}}(k)$, Duijn-Arnold et al. ${ }^{12}$ find that the hf interaction with $\mathrm{Si}$ atoms is larger than that with $\mathrm{C}$ atoms; whereas in a later study, ${ }^{11}$ considerably large hf interaction can be found for a single $\mathrm{Si}$ atom along the $c$ axis and for $\mathrm{C}$ atoms located in the outer shells. For $\mathrm{N}_{\mathrm{C}}(h)$, experimental results on $\mathrm{Si}$ or $\mathrm{C}$ atoms were not available because the EPR signals for ENDOR measurement were too weak. In $6 H \mathrm{SiC}$, Duijn-Arnold et al. ${ }^{12}$ observe that the spin density is localized mainly on $\mathrm{C}$ atoms not only for the quasi-cubic sites but also for the $\mathrm{N}_{\mathrm{C}}(h)$, and no strong hf interaction is found with $\mathrm{Si}$ atoms. For the quasi-cubic N donors, Savchenko et al. ${ }^{13}$ find the strongest hf interaction with $\mathrm{Si}$ atoms close to the $\mathrm{N}$ donor, however considerable $\mathrm{hf}$ interaction is obtained for $\mathrm{C}$ atoms too. In their later study, ${ }^{14}$ large hf splitting is found for several $\mathrm{Si}$ atoms for $\mathrm{N}_{\mathrm{C}}(h)$ and $\mathrm{N}_{\mathrm{C}}\left(k_{1}\right)$. For $\mathrm{N}$ substituting the $k_{2}$ site, they find that the $\mathrm{hf}$ interaction with $\mathrm{C}$ is much stronger. From this result, they conclude that the $\mathrm{N}$ donor at $k_{2}$ site incorporates at $\mathrm{Si}$ site. We note that unambiguous distinction between quasi-cubic sites were reported only in Ref. 14. These contradictory results need in-depth investigation.

In this work, we present hf calculations related to $\mathrm{N}_{\mathrm{C}}$ in $4 H$ and $6 H \mathrm{SiC}$ and new EPR measurements in $6 H \mathrm{SiC}$. 
Our calculations reveal that both in $4 H$ and $6 H$ SiC considerable hf interaction (larger than $5 \mathrm{MHz}$ ) occurs with more $\mathrm{C}$ than $\mathrm{Si}$ atoms. Moreover, for $\mathrm{N}_{\mathrm{C}}(k)$ in $4 H \mathrm{SiC}$ and $\mathrm{N}_{\mathrm{C}}\left(k_{1}\right)$ in $6 \mathrm{H} \mathrm{SiC}$, the hf structures are similar: well observable hf interaction occurs with the third Si neighbour atom along the $c$ axis. The result for $\mathrm{N}_{\mathrm{C}}(k)$ in $4 \mathrm{H} \mathrm{SiC}$ is in good agreement with Son et al.'s study. ${ }^{11}$ For $\mathrm{N}_{\mathrm{C}}\left(k_{2}\right)$ in $6 \mathrm{H}$ $\mathrm{SiC}$, the interaction with the third neighbour Si along the $c$ axis disappears, the spin density is mostly localized on $\mathrm{C}$ atoms, which does not mean that $\mathrm{N}$ donor resides at $\mathrm{Si}$ site. Our new EPR measurements corroborated our $a b$ initio results in $6 \mathrm{H} \mathrm{SiC}$ confirming $\sim 23 \mathrm{MHz}$ hyperfine signal on one ${ }^{29} \mathrm{Si}$ when $\mathrm{N}$ substitutes one of the quasi-cubic sites.

\section{METHOD OF THE CALCULATION}

In order to calculate the hf constants, we used 5.3.3 version of Vienna $A b$ Initio Simulation Package (VASP). ${ }^{15,16}$ Since we had to calculate the electron spin density close to the nuclei accurately, the all-electron projector augmented wave method (PAW) ${ }^{17,18}$ was applied together with plane wave basis set. We utilized the standard PAW-projectors provided by the VASP package. Plane wave cut-off of $420 \mathrm{eV}$ was used, which was sufficient to obtain convergent spin density and hf constants $\left(A_{x x}, A_{y y}, A_{z z}\right)$. For modeling the defects, large 576-atom and 432-atom supercells were applied for $4 \mathrm{H}$ and $6 H \mathrm{SiC}$, respectively. For these supercells, the $\Gamma$-point sampling of the first Brillouin zone sufficed. In $4 H \mathrm{SiC}$, the conduction band minimum (CBM) is at the $M$ point; and in $6 H \mathrm{SiC}$, this minimum lies between the $M$ and $L$ point called $U$ point where the conduction band is relatively flat at the minimum. ${ }^{6}$ Since the $M$ point was projected into the $\Gamma$-point, the corresponding Bloch-states are well sampled to build up the donor wave functions. In $6 \mathrm{H} \mathrm{SiC}$, the results may be less accurate due to smaller number of atoms. However, we focus rather the distribution of the donor wave function and the trend of the relative magnitudes in hf interactions that should be well-captured in our calculations.

It was shown recently ${ }^{19}$ that for the calculation of the hf constants related to point defects in semiconductors, e.g., in SiC, the non-local Heyd-Scuseria-Ernzerhof hybrid functional (HSE06) ${ }^{20,21}$ provides the accurate results with taking the contribution of the spin polarization of the core electrons to the Fermi-contact term into account. However, we applied the semi-local Perdew-Burke-Ernzerhof functional $(\mathrm{PBE})^{22}$ for geometry optimization of $\mathrm{N}$ donors since the spin density of the shallow donor states can be well-described by PBE. We carried out the geometry optimization until the force acting on the atoms was below $0.01 \mathrm{eV} / \AA$. These PBE optimized geometries were used for the HSE06 hf calculations. According to Ref. 19, this approximation caused less than $3 \%$ error in the calculated hf constants.

The EPR measurements were performed on an X-band ( 9.4 GHz) E500 Bruker spectrometer equipped with a continuous He-flow cryostat, allowing the regulation of the sample temperature from 4 to $295 \mathrm{~K}$. The sample was commercial $n$-type substrate $6 H \mathrm{SiC}$ with concentration of nitrogen $\sim 3.3 \times 10^{17} \mathrm{~cm}^{-3}$.

\section{RESULTS AND DISCUSSION}

Now, we provide and discuss our results in detail. The hf values related to $\mathrm{N}$ and relevant $\mathrm{Si}$ atoms are listed in Table I. The hf values obtained for $30 \mathrm{C}$ atoms (on the average) for each center in $4 H$ and $6 H \mathrm{SiC}$ are in the range of 10 and $25 \mathrm{MHz}$. These $\mathrm{C}$ atoms are arranged in groups containing 3-6 atoms, and they reside in the second $(\sim 4-5 \AA$ far from $\mathrm{N})$, fourth $(\sim 6-8 \AA$ far from $\mathrm{N})$, and sixth $(\sim 10-12 \AA$ far from $\mathrm{N}$ ) shells. The maximum hf values for these $\mathrm{C}$ atoms located in the second, fourth, and sixth shells are $\sim 25 \mathrm{MHz}, \sim 20 \mathrm{MHz}$, and $\sim 15 \mathrm{MHz}$, respectively, and they are isotropic, namely, $A_{x x}, A_{y y}$, and $A_{z z}$ are almost equal. The hf interaction with $\mathrm{C}$ atoms placed between these shells is weak, thus the spin density does not continuously decrease with increasing distance from the $\mathrm{N}$ donor but it oscillates. The reason why small hf values can be found for most of $\mathrm{Si}$ atoms is the appearance of the floating states in the interstitial channels around the Si atoms. ${ }^{23}$ Because of this phenomenon, the effective mass approximation used in Refs. 10, 12, and 14 is not valid and it might result in false assignment of the measured spectrum. In addition, in high-frequency ENDOR, it is not too easy to detect $\mathrm{Si}$ atoms with hf constant of larger than $\sim 12 \mathrm{MHz}$ because of the overlap with $\mathrm{C}$ signals. ${ }^{6}$ This fact increases the probability of the false identification. Hereinafter, we analyze each defect one by one.

First, we deal with the $\mathrm{N}$ donor in $4 \mathrm{H} \mathrm{SiC}$. In Fig. 1, the spin density is depicted for $\mathrm{N}_{\mathrm{C}}(h)$ and $\mathrm{N}_{\mathrm{C}}(k)$, respectively. For

TABLE I. The calculated principal values (in $\mathrm{MHz}$ unit) of the hf tensors for ${ }^{14} \mathrm{~N}$ and ${ }^{29} \mathrm{Si}$ in $\mathrm{N}_{\mathrm{C}}(h, k)$ in $4 H$ and in $\mathrm{N}_{\mathrm{C}}\left(h, k_{1}, k_{2}\right)$ in $6 H \mathrm{SiC}$. The labelled numbers are the measured values. Other assignments in Ref. 14 to ${ }^{29} \mathrm{Si}$ are given in the text. The distances $(d)$ between the $\mathrm{N}$ atom and proximate nuclei are also given. The signs cannot be determined in the measurements.

\begin{tabular}{|c|c|c|c|c|c|c|}
\hline & Center & Atoms & $d(\AA)$ & $A_{x x}$ & $A_{y y}$ & $A_{z z}$ \\
\hline \multirow[t]{9}{*}{$4 H$} & $\mathrm{~N}_{\mathrm{C}}(h)$ & $\mathrm{N}$ & & 7.57 & 7.57 & 8.06 \\
\hline & & & & $2.82^{\mathrm{a}}$ & $2.82^{\mathrm{a}}$ & $3.06^{\mathrm{a}}$ \\
\hline & & $\mathrm{Si} \times 3$ & 6.72 & -11.23 & -11.24 & -11.08 \\
\hline & $\mathrm{N}_{\mathrm{C}}(k)$ & $\mathrm{N}$ & & 46.45 & 46.45 & 46.50 \\
\hline & & & & $50.97^{\mathrm{a}}$ & $50.97^{\mathrm{a}}$ & $50.98^{\mathrm{a}}$ \\
\hline & & $\mathrm{Si} \times 3$ & 1.93 & -5.56 & -5.56 & -13.20 \\
\hline & & & & $5.06^{\mathrm{b}}$ & $5.94^{\mathrm{b}}$ & $14.25^{\mathrm{b}}$ \\
\hline & & $\mathrm{Si} \times 1$ & 3.18 & -39.34 & -39.34 & -38.66 \\
\hline & & & & $41.31^{\mathrm{b}}$ & $41.31^{b}$ & $41.07^{\mathrm{b}}$ \\
\hline \multirow[t]{12}{*}{$6 H$} & $\mathrm{~N}_{\mathrm{C}}(h)$ & $\mathrm{N}$ & & 2.00 & 2.00 & 2.76 \\
\hline & & & & $2.33^{\mathrm{a}}$ & $2.33^{\mathrm{a}}$ & $2.74^{\mathrm{a}}$ \\
\hline & $\mathrm{N}_{\mathrm{C}}\left(k_{1}\right)$ & $\mathrm{N}$ & & 32.86 & 32.86 & 32.85 \\
\hline & & & & $33.56^{\mathrm{a}}$ & $33.56^{\mathrm{a}}$ & $33.58^{\mathrm{a}}$ \\
\hline & & & & $33.77^{\mathrm{c}}$ & $33.77^{\mathrm{c}}$ & $33.77^{\circ}$ \\
\hline & & $\mathrm{Si} \times 3$ & 1.93 & -2.70 & -2.67 & -8.29 \\
\hline & & $\mathrm{Si} \times 1$ & 3.18 & -18.40 & -18.40 & -17.92 \\
\hline & & & & $23.26^{\mathrm{c}}$ & $23.26^{\mathrm{c}}$ & $22.77^{\circ}$ \\
\hline & $\mathrm{N}_{\mathrm{C}}\left(k_{2}\right)$ & $\mathrm{N}$ & & 32.60 & 32.60 & 32.71 \\
\hline & & & & $33.22^{\mathrm{a}}$ & $33.22^{\mathrm{a}}$ & $33.23^{\mathrm{a}}$ \\
\hline & & & & $33.20^{\mathrm{c}}$ & $33.20^{\mathrm{c}}$ & $33.20^{\mathrm{c}}$ \\
\hline & & $\mathrm{Si} \times 3$ & 1.93 & -2.59 & -2.69 & -9.79 \\
\hline
\end{tabular}

${ }^{\mathrm{a}}$ Experimental data are taken from Ref. 10.

${ }^{\mathrm{b}}$ Experimental data are taken from Ref. 11.

${ }^{\mathrm{c}}$ Our EPR measurement. 

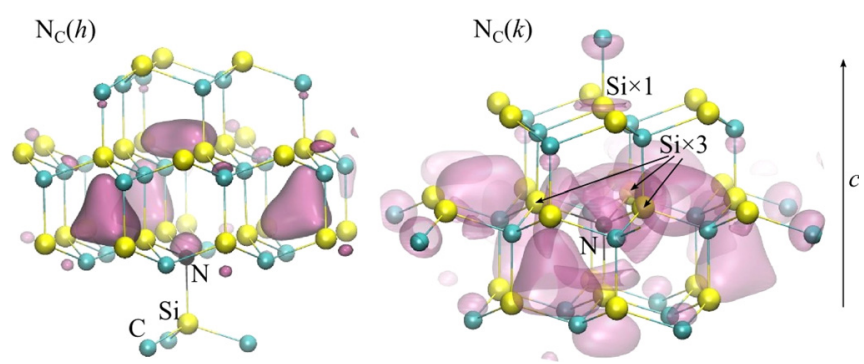

FIG. 1. Calculated spin density for $\mathrm{N}_{\mathrm{C}}$ at $h$ and $k$ sites in $4 H \mathrm{SiC}$ (isovalues: $0.00311 / \AA^{3}$ and $0.00201 / \AA^{3}$ for $h$ and $k$ sites, respectively). Floating states appear in the internal channel of $\mathrm{Si}$ atoms in both cases.

$\mathrm{N}_{\mathrm{C}}(h)$, the hf interaction is notable mainly with $\mathrm{C}$ atoms. However, three $\mathrm{Si}$ atoms $(\mathrm{Si} \times 3)$ can be found with $\sim-11 \mathrm{MHz}$ isotropic hf values, as well as additional $\mathrm{Si}$ atoms with $6-8 \mathrm{MHz}$ of isotropic hf values. The numbers of these $\mathrm{Si}$ atoms are about the half of those of the $\mathrm{C}$ atoms on which the spin density is localized. The hf interaction with $\mathrm{N}$ atom is slightly anisotropic and weak, and $\sim 2.5$ times larger than the measured value found in Ref. 10 (see Table I). For $\mathrm{N}_{\mathrm{C}}(k)$, we find strong isotropic hf interaction with $\mathrm{N}$ donor $(\sim 46 \mathrm{MHz})$ and with a $\mathrm{Si}$ atom $(\mathrm{Si} \times 1, \sim-39 \mathrm{MHz})$ along the $c$ axis. Besides, anisotropic hf interaction occurs with three nearest neighbour $\mathrm{Si}$ atoms $(\mathrm{Si} \times 3)$ located in the basal plane (see Table I). Our results on hf signals of ${ }^{29} \mathrm{Si},{ }^{13} \mathrm{C}$, and ${ }^{14} \mathrm{~N}$ agree the measured data reported in Refs. 10 and 11 within $10 \%$. Contrarily, Ref. 12 reports anisotropic interaction with $\mathrm{Si}$ atoms (largest hf constants: $A_{x x}=A_{y y}=5.28 \mathrm{MHz}$, $A_{z z}=9.06 \mathrm{MHz}$ ), and mainly isotropic hf interaction with $\mathrm{C}$ atoms ( $\sim 5 \mathrm{MHz}$ of maximum value). They cannot find as large hf values as in Ref. 11 neither for Si nor for $\mathrm{C}$ atoms since they analyzed only the lower ENDOR frequency range, thus the $\mathrm{Si}$ and $\mathrm{C}$ shells close to the $\mathrm{N}$ donor are not detected. ${ }^{11}$ In conclusion, our result for $\mathrm{N}_{\mathrm{C}}(k)$ supports the measurements and interpretation of hf signals in Ref. 11.

Next, we study the hf signals of $\mathrm{N}_{\mathrm{C}}$ in $6 \mathrm{H} \mathrm{SiC}$. Fig. 2 shows the distribution of the spin density for $\mathrm{N}_{\mathrm{C}}(h), \mathrm{N}_{\mathrm{C}}\left(k_{1}\right)$, and $\mathrm{N}_{\mathrm{C}}\left(k_{2}\right)$. For $\mathrm{N}_{\mathrm{C}}(h)$, considerable isotropic hf constants occur for $\mathrm{C}$ atoms and small, slightly anisotropic hf values for $\mathrm{N}$ atom (see Table $\mathrm{I}$ ). The interaction with $\mathrm{Si}$ atoms is anisotropic and $A_{z z}<3 \mathrm{MHz}$. In the case of $\mathrm{N}_{\mathrm{C}}\left(k_{1}\right)$ as for $\mathrm{N}_{\mathrm{C}}(k)$ in $4 H \mathrm{SiC}$, we find strong isotropic hf interaction with $\mathrm{N}(\sim 33 \mathrm{MHz})$ and with the third neighbour $\mathrm{Si}$ atom $(\mathrm{Si} \times 1$, $\sim-18 \mathrm{MHz}$ ) along the $c$ axis, and anisotropic interaction with three nearest $\mathrm{Si}$ atoms in the basal plane. For $\mathrm{N}_{\mathrm{C}}\left(k_{2}\right)$, the hf constant for $\mathrm{N}$ is isotropic, and the value of it is almost the same as that for $\mathrm{N}_{\mathrm{C}}\left(k_{1}\right)$. However, large hf value for $\mathrm{Si} \times 1$ is missing. The strongest hf interaction with $\mathrm{Si}$ occurs for three nearest neighbour $\mathrm{Si}$ atoms $\left(\mathrm{Si} \times 3, A_{x x} \approx A_{y y}\right.$ $\left.\approx-2.6 \mathrm{MHz}, A_{z z} \approx-9.8 \mathrm{MHz}\right)$. The lack of the hf interaction with $\mathrm{Si} \times 1$ atom is due to the long distance $(\sim 8.2 \AA)$ of this $\mathrm{Si}$ atom from the $\mathrm{N}$ donor along the $c$-axis. Isotropic hf interaction showing toroidal spin density (see $\mathrm{N}_{\mathrm{C}}(k)$ in Fig. 1 or $\mathrm{N}_{\mathrm{C}}\left(k_{1}\right)$ in Fig. 2) can be found for three equivalent $\mathrm{Si}$ atoms at $\sim 6.7 \AA$ far from $\mathrm{N}$ but not along $c$-axis. The isotropic hf interaction seems to move from $\mathrm{Si} \times 1$ to that three $\mathrm{Si}$ atoms, however, the value of the hf splitting is small, only $\sim 3.2 \mathrm{MHz}$.

Comparing our results with previous experimental findings in $6 \mathrm{H} \mathrm{SiC}$, we can conclude the followings. For $\mathrm{N}_{\mathrm{C}}(h)$, the results in Ref. 12 are similar to ours, however the highest hf constant for $\mathrm{C}$ atom is only $\sim 10 \mathrm{MHz}$, and for $\mathrm{Si}$ atoms is less than $3 \mathrm{MHz}$ according to their interpretation of the measured EPR spectrum. Our results on Si go opposite to those in Ref. 14: isotropic hf values of $\sim 11 \mathrm{MHz}$ and $\sim 14 \mathrm{MHz}$ are reported for $\mathrm{Si}$ located in the first and the second shell of $\mathrm{N}_{\mathrm{C}}(h)$ donor. For $\mathrm{N}_{\mathrm{C}}\left(k_{1}\right)$ in Ref. 14, two large isotropic hf splittings $(\sim 23$ and $\sim 15 \mathrm{MHz}$ ) were assigned to $\mathrm{Si}$ atoms located in the first or third shell of N. In contrast, we can find considerable hf interaction only with a single $\mathrm{Si}$ atom $(\mathrm{Si} \times 1)$. For $\mathrm{N}_{\mathrm{C}}\left(k_{2}\right)$ in Ref. 14 , they reported spin density localized on $\mathrm{C}$ atoms, and only small isotropic hf interaction $(\sim 5 \mathrm{MHz})$ was reported for $\mathrm{Si}$ atoms. Since the largest hf interaction was observed on $\mathrm{C}$ atoms, they concluded that this center was $\mathrm{N}_{\mathrm{Si}}\left(k_{2}\right)$, i.e., $\mathrm{N}$ would substitute $\mathrm{Si}$ atom in $\mathrm{SiC}$ lattice. Our calculation reveals that this conclusion was not well grounded since large hf splitting on Si nuclei is missing for $\mathrm{N}_{\mathrm{C}}\left(k_{2}\right)$. For the two unresolved quasi-cubic sites, Ref. 10 reported isotropic hf values for $\mathrm{Si}$ with less than $7 \mathrm{MHz}$ and for $\mathrm{C}$ atoms with less than $5 \mathrm{MHz}$. In contrast, in Ref. 12 , less than $4 \mathrm{MHz}$ isotropic hf constants were obtained for $\mathrm{Si}$ and less than $10 \mathrm{MHz}$ for $\mathrm{C}$ atoms. They explained this contradiction by the strong overlap of the $\mathrm{Si}$ and $\mathrm{C}$ signals. The results in Ref. 12 are closer to our findings, however unambiguous conclusion cannot be made since the quasi-cubic sites were not resolved.

Our findings on $\mathrm{N}_{\mathrm{C}}\left(k_{1}\right)$ and $\mathrm{N}_{\mathrm{C}}\left(k_{2}\right)$ are validated by our new EPR measurements. Fig. 3 shows the EPR spectra of the shallow $\mathrm{N}$ donors in $6 H \mathrm{SiC}$ measured at $55 \mathrm{~K}$ for $\mathbf{B} \perp c$. Two hf lines of $\mathrm{N}_{\mathrm{C}}\left(k_{1}\right)$ with splittings of $A_{x x}=A_{y y}=23.26 \mathrm{MHz}$ and $A_{z z}=22.77 \mathrm{MHz}$ were observed. Their intensity ratio with the main line of $\sim 5 \%$ indicates that they are from the hf interaction with one ${ }^{29} \mathrm{Si}$ atom on the bond along to the $c$ axis. For
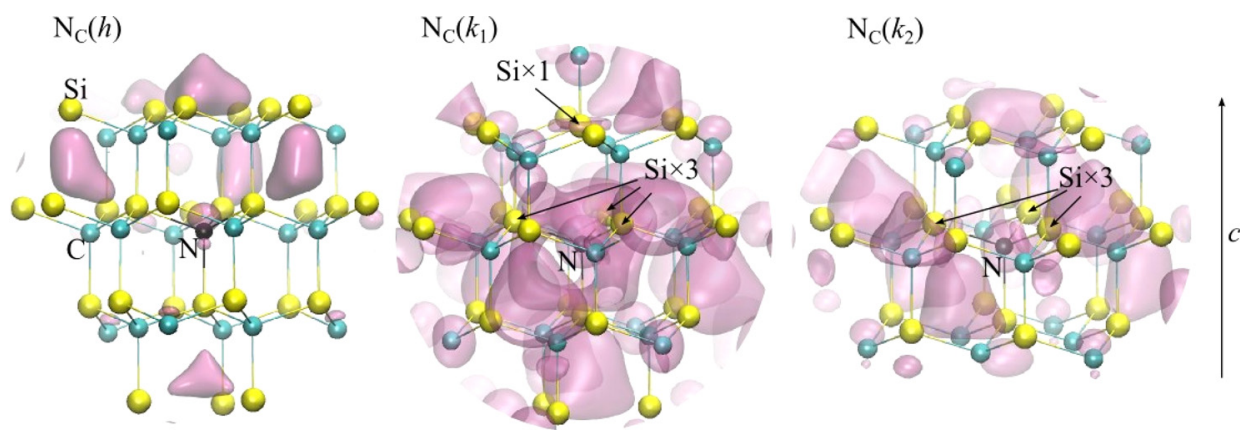

FIG. 2. Calculated spin density for $\mathrm{N}_{\mathrm{C}}$ at $h, k_{1}$, and $k_{2}$ sites in $6 \mathrm{H} \mathrm{SiC} \mathrm{(isoval-}$ ues: $0.00311 / \AA^{3}, 0.00111 / \AA^{3}, 0.0024$ $1 / \AA^{3}$ for $h, k_{1}, k_{2}$ sites, respectively). Floating states appear in the internal channels around Si atoms. 


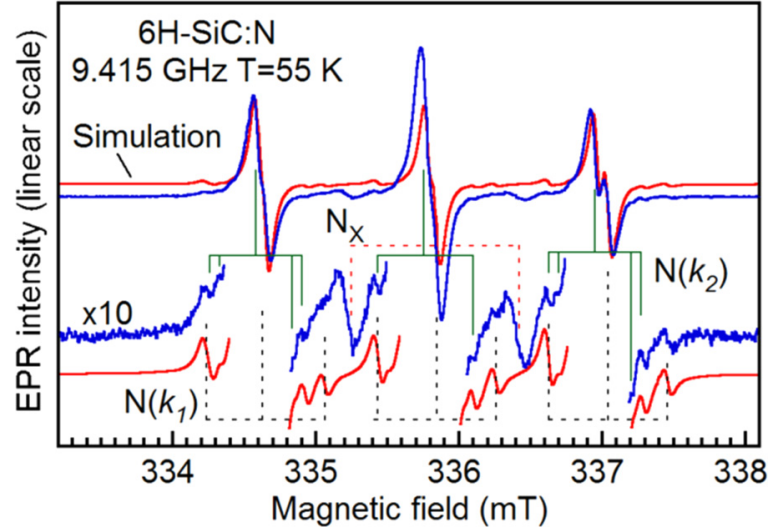

FIG. 3. EPR spectrum of the shallow $\mathrm{N}$ donor in $6 H \mathrm{SiC}$ measured for $\mathbf{B} \perp c$ and the simulated spectrum of $\mathrm{N}_{\mathrm{C}}\left(k_{1}\right)$ and $\mathrm{N}_{\mathrm{C}}\left(k_{2}\right)$ with assuming the hf interactions with one ${ }^{29} \mathrm{Si}(\sim 23.26 \mathrm{MHz})$ for $\mathrm{N}_{\mathrm{C}}\left(k_{1}\right)$ and $6(\sim 18.40 \mathrm{MHz})$ and 3 equivalent ${ }^{13} \mathrm{C}(\sim 14.63 \mathrm{MHz})$ atoms for $\mathrm{N}_{\mathrm{C}}\left(k_{2}\right)$ with Lorentzian lineshape and a linewidth of $0.62 \mathrm{G}$. The middle line of the simulated spectrum is smaller than that of the experimental one since the $\mathrm{N}_{\mathrm{C}}(h)$ line is not included in the simulation. The broad shoulder at low magnetic field in experimental spectrum is due to the overlapping with smaller splitting hf lines of ${ }^{13} \mathrm{C}$ and ${ }^{29} \mathrm{Si}$, which are not included in the simulated spectrum.

$\mathrm{N}_{\mathrm{C}}\left(k_{2}\right)$, two pairs of hf lines were observed for $\mathbf{B} \perp c$ with hf splittings of $\sim 18.40 \mathrm{MHz}$ and $14.63 \mathrm{MHz}$, which are in good agreement with previous ENDOR study. ${ }^{14}$ As shown in Fig. 3 , these $\mathrm{C}$ hf structures are best fitted with assuming the hf interactions with 6 and 3 equivalent ${ }^{13} \mathrm{C}$ atoms, respectively, as predicted from the calculations $(\sim 20.4 \mathrm{MHz}$ for six $\mathrm{C}$-atoms and $\sim 14.6 \mathrm{MHz}$ for three $\mathrm{C}$ atoms). The agreement between EPR and calculations in the Si hf structure of $\mathrm{N}_{\mathrm{C}}\left(k_{1}\right)$ and the $\mathrm{C}$ hf structures of $\mathrm{N}_{\mathrm{C}}\left(k_{2}\right)$ supports the conclusion that the missing of the $\mathrm{Si}$ hf structure of $\mathrm{N}_{\mathrm{C}}\left(k_{2}\right)$ can be explained by the nature of the floating states, i.e., the spin density is distributed in the interstitial channels around the $\mathrm{Si}$ atoms, and it does not require the model of $\mathrm{N}$ substituting $\mathrm{Si}$ atom at $k_{2}$ site in $6 \mathrm{H} \mathrm{SiC}$.

\section{SUMMARY}

In summary, we studied the hf structure of $\mathrm{N}_{\mathrm{C}}$ at different lattice sites in $4 H$ and $6 H \mathrm{SiC}$. We show that the spin density appears mainly on $\mathrm{C}$ atoms and in the interstitial channels around $\mathrm{Si}$ atoms. Hexagonal and quasi-cubic $\mathrm{N}$ donors can be distinguished by means of the hf value for the $\mathrm{N}$ donor. Moreover, the two quasi-cubic sites in $6 \mathrm{H}$ $\mathrm{SiC}$ can also be resolved since hf value of $\sim 23 \mathrm{MHz}$ can be observed for a single ${ }^{29} \mathrm{Si}$ isotope located on the $c$ axis only for $\mathrm{N}_{\mathrm{C}}\left(k_{1}\right)$. Based on the agreement with results in Ref. 11 for $4 H \mathrm{SiC}$ and with our new EPR data for $6 H$
$\mathrm{SiC}$, we conclude that $\mathrm{N}$ donor definitely substitutes $\mathrm{C}$ sublattice in hexagonal $\mathrm{SiC}$. The interpretation and/or the assignments in the other EPR/ENDOR studies ${ }^{10,12,14}$ need further investigations.

\section{ACKNOWLEDGMENTS}

Support from EU FP7 project DIAMANT (Grant No. 270197), the MTA Lendület program of the Hungarian Academy of Sciences, the Swedish Foundation for Strategic Research (SSF), the Knut and Alice Wallenberg Foundation as well as the National Supercomputer Center in Sweden (SNIC 001-12-275) is acknowledged.

${ }^{1}$ Properties of Silicon Carbide, edited by G. Harris, EMIS datareviews series (INSPEC, Institution of Electrical Engineers, 1995).

${ }^{2}$ W. F. Koehl, B. B. Buckley, F. J. Heremans, G. Calusine, and D. D. Awschalom, Nature 479, 84 (2011).

${ }^{3}$ S. Castelletto, B. C. Johnson, V. Ivády, N. Stavrias, T. Umeda, A. Gali, and T. Ohshima, Nature Mater. 13, 151 (2014).

${ }^{4}$ A. L. Falk, B. B. Buckley, G. Calusine, W. F. Koehl, V. V. Dobrovitski, A. Politi, C. A. Zorman, P. X.-L. Feng, and D. D. Awschalom, Nat. Commun. 4, 1819 (2013).

${ }^{5}$ M. Ikeda, H. Matsunami, and T. Tanaka, Phys. Rev. B 22, 2842 (1980).

${ }^{6}$ N. T. Son, J. Isoya, T. Umeda, I. G. Ivanov, A. Henry, T. Ohshima, and E. Janzén, Appl. Magn. Reson. 39, 49 (2010).

${ }^{7}$ A. Gali, P. Deák, N. T. Son, and E. Janzén, Appl. Phys. Lett. 83, 1385 (2003).

${ }^{8}$ R. Rurali, P. Godignon, J. Rebollo, E. Hernández, and P. Ordejón, Appl. Phys. Lett. 82, 4298 (2003).

${ }^{9}$ M. Bockstedte, A. Mattausch, and O. Pankratov, Appl. Phys. Lett. 85, 58 (2004).

${ }^{10}$ S. Greulich-Weber, Phys. Status Solidi A 162, 95 (1997).

${ }^{11}$ N. T. Son, E. Janzén, J. Isoya, and S. Yamasaki, Phys. Rev. B 70, 193207 (2004).

${ }^{12}$ A. v. Duijn-Arnold, R. Zondervan, J. Schmidt, P. G. Baranov, and E. N. Mokhov, Phys. Rev. B 64, 085206 (2001).

${ }^{13}$ D. V. Savchenko, E. N. Kalabukhova, V. S. Kiselev, J. Hoentsch, and A. Pöppl, Phys. Status Solidi B 246, 1908 (2009).

${ }^{14}$ D. V. Savchenko, E. N. Kalabukhova, A. Pöppl, and B. D. Shanina, Phys. Status Solidi B 249, 2167 (2012).

${ }^{15}$ G. Kresse and J. Hafner, Phys. Rev. B 49, 14251 (1994).

${ }^{16}$ G. Kresse and J. Furthmüller, Phys. Rev. B 54, 11169 (1996).

${ }^{17}$ P. E. Blöchl, Phys. Rev. B 50, 17953 (1994).

${ }^{18}$ G. Kresse and D. Joubert, Phys. Rev. B 59, 1758 (1999).

${ }^{19}$ K. Szász, T. Hornos, M. Marsman, and A. Gali, Phys. Rev. B 88, 075202 (2013).

${ }^{20}$ J. Heyd, G. E. Scuseria, and M. Ernzerhof, J. Chem. Phys. 118, 8207 (2003).

${ }^{21}$ A. V. Krukau, O. A. Vydrov, A. F. Izmaylov, and G. E. Scuseria, J. Chem. Phys. 125, 224106 (2006).

${ }^{22}$ J. P. Perdew, K. Burke, and M. Ernzerhof, Phys. Rev. Lett. 77, 3865 (1996).

${ }^{23}$ Y.-i. Matsushita, S. Furuya, and A. Oshiyama, Phys. Rev. Lett. 108, 246404 (2012). 